\title{
BMJ Open Body mass index in early and middle adult life: prospective associations with myocardial infarction, stroke and diabetes over a 30 -year period: the British Regional Heart Study
}

\author{
Christopher G Owen, ${ }^{1}$ Venediktos V Kapetanakis, ${ }^{1}$ Alicja R Rudnicka, ${ }^{1}$ \\ Andrea K Wathern, ${ }^{1}$ Lucy Lennon, ${ }^{2}$ Olia Papacosta, ${ }^{2}$ Derek G Cook, ${ }^{1}$ \\ S Goya Wannamethee, ${ }^{2}$ Peter H Whincup ${ }^{1}$
}

To cite: Owen CG,

Kapetanakis VV,

Rudnicka AR, et al. Body

mass index in early and

middle adult life: prospective associations with myocardial infarction, stroke and diabetes over a 30-year period: the British Regional Heart Study. BMJ Open 2015;5:e008105.

doi:10.1136/bmjopen-2015008105

- Prepublication history and additional material is available. To view please visit the journal (http://dx.doi.org/ 10.1136/bmjopen-2015008105).

Received 5 March 2015 Revised 16 July 2015 Accepted 24 July 2015

CrossMark

\footnotetext{
${ }^{1}$ Population Health Research Institute, St George's, University of London, London, UK

${ }^{2}$ Department of Primary Care and Population Health, UCL Medical School, London, UK
}

Correspondence to Dr Christopher G Owen; cowen@sgul.ac.uk

\section{ABSTRACT}

Objectives: Adiposity in middle age is an established risk factor for cardiovascular disease and type 2 diabetes; less is known about the impact of adiposity from early adult life. We examined the effects of high body mass index (BMI) in early and middle adulthood on myocardial infarction (MI), stroke and diabetes risks.

Design: A prospective cohort study.

Participants: 7735 men with BMI measured in middle age (40-59 years) and BMI ascertained at 21 years from military records or participant recall.

\section{Primary and secondary outcome measures:}

30-year follow-up data for type 2 diabetes, $\mathrm{Ml}$ and stroke incidence; Cox proportional hazards models were used to examine the effect of BMl at both ages on these outcomes, adjusted for age and smoking status.

Results: Among 4846 (63\%) men (with complete data), a $1 \mathrm{~kg} / \mathrm{m}^{2}$ higher BMI at 21 years was associated with a $6 \%(95 \% \mathrm{Cl} 4 \%$ to $9 \%)$ higher type 2 diabetes risk, compared with a $21 \%(95 \% \mathrm{Cl} 18 \%$ to $24 \%)$ higher diabetes risk for a $1 \mathrm{~kg} / \mathrm{m}^{2}$ higher BMI in middle age (hazard ratio (HR) $1.21,95 \% \mathrm{Cl} 1.18$ to 1.24 ). Higher BMI in middle age was associated with a $6 \%$ $(95 \% \mathrm{Cl} 4 \%$ to $8 \%)$ increase in $\mathrm{Ml}$ and a $4 \%(95 \% \mathrm{Cl}$ $1 \%$ to $7 \%$ ) increase in stroke; BMI at 21 years showed no associations with $\mathrm{MI}$ or stroke risk.

Conclusions: Higher BMI at 21 years of age is associated with later diabetes incidence but not MI or stroke, while higher BMI in middle age is strongly associated with all outcomes. Early obesity prevention may reduce later type 2 diabetes risk, more than $\mathrm{MI}$ and stroke.

\section{INTRODUCTION}

Increased adiposity in middle age and later life is an important risk factor for type 2 diabetes and cardiovascular disease,

\section{Strengths and limitations of this study}

- This investigation is based on a geographically and socially representative cohort study with high response rates and exceptionally high follow-up rates.

- Linkage of military record data to this established middle-aged cohort provides novel information on early life exposures.

- The limited number of study participants with high levels of body mass index (BMI) in early life will have limited the power of the study for detection of the effects of BMI in early adult life on risks of myocardial infarction and stroke, though they were detectable for diabetes.

- Effects of high early BMI on diabetes may be potentially reversible by subsequent weight loss.

- Findings have important implications for type 2 diabetes prevention.

especially coronary heart disease (CHD).$^{1-5}$ There has been a worldwide increase in the prevalences of overweight and obesity in recent decades, particularly in higher income countries. ${ }^{6-8}$ However, overweight and obesity are increasingly affecting younger as well as older people. ${ }^{7}$ Since high levels of adiposity track strongly from childhood and early adulthood to middle age, most people who become overweight in early adult life will be overweight or obese in middle age. ${ }^{9} 10$ There is growing concern about the long-term health consequences of increased exposure to adiposity from early adult life, which may exacerbate the risks of cardiovascular disease and type 2 diabetes in later life. $^{11} 12$

To understand the consequences of adiposity over the life course requires studies with 
accurate data on adiposity at several points of the life course, including early adult life, middle age and in later life, with extended follow-up for relevant outcomes. ${ }^{12}{ }^{13}$ Birth cohort studies often have information on adiposity both before and during middle age, ${ }^{14-16}$ but generally have populations which are too young to have large numbers of chronic disease events in later life. Many prospective studies have data on adiposity in middle age and its relation to subsequent chronic disease outcomes, ${ }^{2}$ but few of these also have information on adiposity in early adult life. ${ }^{12}$

We have therefore used a novel approach to provide new information on this issue, obtaining data on measured weight and height in early adult life (at age 21 years) from military service records for participants in an established cohort of almost 8000 men in whom body mass index (BMI) has been studied in detail from middle age (40-59 years) onwards, and for whom at least 30 years of follow-up data on cardiovascular outcomes and diabetes are available. For the purpose of this report, BMI in early adult life (mean age 21 years) and middle age (mean age 50 years) will be referred to as BMI-21 and BMI-50.

\section{METHODS}

\section{The British Regional Heart Study}

The British Regional Heart Study (BRHS) is a prospective study of cardiovascular disease, and type 2 diabetes among middle-aged and older British men. It is based on 7735 men born between 1919 and 1939 who were recruited in 1978-1980 aged 40-59 years from a single general practice in 24 British towns $(78 \%$ response rate), ${ }^{17}$ and were followed up until the present. Study men completed a detailed questionnaire on entry to the study (including information on pre-existing cardiovascular disease, type 2 diabetes and other medical conditions, smoking status, physical activity, alcohol intake and social class) and had measurements of weight and height, measured with participants in light clothing without shoes. Weight was measured to the last $0.1 \mathrm{~kg}$ using regularly calibrated scales and height to the last complete $0.1 \mathrm{~cm}$ using a Harpenden stadiometer. Participants then completed periodic postal questionnaires about their health in 1983-1985, 1992 and 1996; in 1996, they were asked to recall their weight at age 21 years. Men have been followed up over a 30-year period for mortality, morbidity and disability with $<2 \%$ loss to follow-up.

\section{Follow-up}

Study participants were followed prospectively from the baseline examination at 40-59 years for all-cause mortality, cardiovascular morbidity and diabetes incidence from baseline to June 2010. Those with a doctor diagnosis of myocardial infarction (MI; $n=134)$, stroke $(n=19)$ and diabetes $(n=50)$ at baseline $(n=195$ in all $)$ were excluded. Follow-up has been achieved for $98 \%$ of the cohort. ${ }^{17}$ Information on deaths was collected through National Health Service Central Registers; death certificates were coded using the International Classification of Diseases, Ninth Revision (ICD-9). Fatal MI was defined as ICD-9 codes 410-414 and fatal stroke as ICD-9 codes 430-438. Information on non-fatal MI and stroke events was obtained according to ongoing general practitioner reports and two-yearly medical record reviews. ${ }^{17} \mathrm{~A}$ non-fatal MI was diagnosed according to WHO criteria. ${ }^{18}$ Non-fatal stroke events were those that produced a neurological deficit that was present for more than $24 \mathrm{~h}$. New diabetes diagnoses (including date) were also obtained from medical record reviews.

\section{Obtaining information on weight and height in early adult life}

Since most men in the BRHS cohort (born 1919-1939) would have undertaken military service in early adulthood, either during World War II (1939-1945) or during UK National Service (1945-1963), we sought information on weight in early adult life from military service records. In 2007, a questionnaire was sent to all surviving men enquiring about military service in early adulthood, including details of service period and service number where available, and permission was sought to obtain service medical records (archived at TNT Ltd, Swadlincote, Derbyshire). We have used this data source to obtain measurements of height and weight, which were recorded at service entry (in both service and medical records) and formed part of a standard military medical classification. ${ }^{19}$

\section{Statistical methods}

We have previously outlined the methodology used to obtain weight at 21 years. ${ }^{20}$ In brief, when a record of weight measurement was recorded in service records between 20 and 22 years, this was used directly as an estimate of weight at 21 years. In the absence of measured weight between 20 and 22 years, a weight recorded between either 17 and 19 or 23 and 25 years was used to estimate weight at 21 years from a multilevel model fitted using all weight measurements recorded, adjusting for age (allowing for a quadratic relationship) and period of enlistment; including pre-World War II (19341938), War (1939-1945) and post-War periods (19461950, 1951-1955, 1956-1975). The model included a random intercept allowing for clustering of measures within individual, and a random slope for the linear term of age allowing person-specific age slopes to be determined. Where measured weight was not recorded, recalled weight in 1996 was used, adjusted for recall bias quantified by comparisons of measured and recalled weight at 21 years (available in 694 individuals). Modest overestimation of true weight among thinner men was observed (mean estimated bias across the range of measured weight was $1.5 \mathrm{~kg}$ with a maximum of $6.9 \mathrm{~kg}$ estimated at the lowest limit of the range of measured weight; see online supplementary figure S1). Height 
measurements recorded in military records were used to provide an estimate of height at 21 years using similar methods as for weight. BMI at 21 years was calculated as weight/height squared in $\mathrm{kg} / \mathrm{m}^{2}$.

The exact dates of first MI (fatal or non-fatal), first stroke (fatal or non-fatal) and diagnosis of diabetes were recorded over a 30-year follow-up period from study entry. Incidence rates for all outcomes were summarised by quintiles of BMI-21 to examine trends. A Cox proportional hazards model was used to assess the separate effects of BMI-21 and BMI-50 on the risks of all outcomes (adjusting for age and smoking status at baseline, and town as a fixed effect). Additionally, the effect of BMI-50 on the risk of each outcome was stratified by quintiles of BMI-21 to examine evidence for effect modification. Metaregression of regression coefficients from the stratified analysis were used to examine tests for trend. The effect of BMI on each outcome was also examined using a life course approach, by using trajectories of exposure to high BMI at the two ages (BMI-21 and BMI-50). A high BMI was defined when an individual was on/above the 75th centile of BMI distribution at a specific age. This provided four mutually exclusive trajectories to examine the life course patterning of disease risk, adjusting for town (as fixed effect), age and smoking status.

\section{RESULTS}

In all, 4842 men (63\% of the original cohort) had data on height and weight at both ages (ie, BMI-21 and BMI-50), smoking at BRHS baseline and 30 years of follow-up data for type 2 diabetes, MI and stroke. Weight data at 21 years of age were based on military records for 2205 (44\%) men; measured weight at age 2022 years was obtained directly for 1258 men and imputed from weights between 17 and 19 years or between 23 and 25 years of age for 947 men. Weight at age 21 years was recalled from middle age for the remaining 2832 men. A subset of 694 men with both recalled and measured weight in early adult life allowed bias in recalled weight to be quantified; modest overestimation of true weight among thinner men was observed (see online supplementary figure S1). Similar numbers were obtained for height at 21 years of age, with 1244 men measured between 20 and 22 years of age, 963 measured between 17 and 19 or 23 and 25 years and with 2830 imputed from middle age (allowing for a very small amount of shrinkage). Mean BMI-50 was only marginally higher among the 2890 men excluded from analysis compared with those included (25.6 vs $25.4 \mathrm{~kg} / \mathrm{m}^{2}$, $\mathrm{p}=0.025$ ).

Table 1 shows the anthropometric characteristics of the cohort at 21 and 50 years of age, overall and by quintiles of BMI in early adulthood. Weight and BMI at 50 years increased with higher quintiles of BMI in early adult life (BMI-21). Moreover, prevalences of overweight (defined as BMI $\geq 25 \mathrm{~kg} / \mathrm{m}^{2}$ ) and obesity (defined as

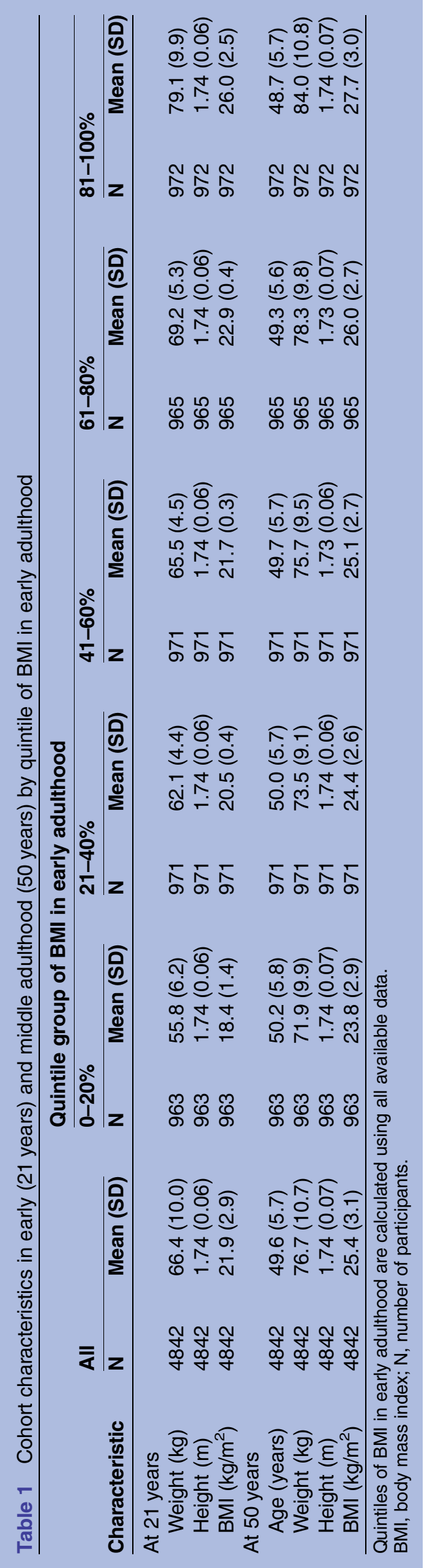


BMI $\geq 30 \mathrm{~kg} / \mathrm{m}^{2}$ ) were considerably higher at 50 years $(46 \%, 7.3 \%)$ compared with prevalence at 21 years $(9.6 \%, 1.5 \%)$. Height remained largely stable between early adult life and middle age with a minimal amount of shrinkage.

Table 2 summarises the incidence rates for diabetes, MI and stroke (fatal and non-fatal) within the cohort overall, and by quintiles of BMI-21 and BMI-50. While there was no evidence of a trend in incidence rates for MI or stroke (fatal and non-fatal) across quintiles of BMI-21, incidence rates of diabetes appeared higher among men who were in the upper quintile of BMI (the 81 st-100th centile) in early life. Incidence rates for diabetes, MI (fatal and non-fatal) and non-fatal stroke appeared positively associated with quintiles of BMI-50.

Table 3 shows hazard ratios (HRs) for each outcome per unit increase in BMI (per $1 \mathrm{~kg} / \mathrm{m}^{2}$ ), separately at 21 and 50 years of age. A $1 \mathrm{~kg} / \mathrm{m}^{2}$ higher BMI-21 was associated with a $6 \%$ higher risk for diabetes in later life (HR $1.06,95 \%$ CI 1.04 to 1.09 ), but not with a higher MI or stroke risk. BMI-50 was strongly associated with higher diabetes risk (HR 1.21, 95\% CI 1.18 to 1.24)three times the effect size for BMI-21-and also with higher risks of MI (HR 1.06, 95\%CI 1.04 to 1.08) and stroke (HR 1.04, 95\% CI 1.01 to 1.07). Fatal MI and fatal stroke showed patterns broadly similar to those for all fatal and non-fatal MI and stroke events, respectively.

Table 4 shows the associations between life course BMI trajectories on cardiometabolic outcomes in later life, expressed as HRs from the reference trajectory $(0-$ $0)$, that is, participants with low levels of BMI at both 21 and 50 years of age. High BMI-50 with or without high BMI-21 was associated with approximately a threefold higher risk of diabetes, and a 30-60\% higher risk of MI (including fatal MI). High BMI-21 with high BMI-50 was associated with a marked increase in diabetes risk and to a lesser extent in MI; high BMI-21 without BMI-50 was not associated with increased risks of diabetes or cardiovascular disease.

The influence of BMI-21 on the associations between BMI-50 and each outcome is summarised in table 5. The risk of diabetes associated with high BMI-50 appeared slightly weaker among men in the lowest quintile of BMI-21, but there was no strong evidence of interaction ( $p=0.19$ for difference in effect of BMI- 50 by quintile of BMI-21-table 5). The associations between BMI-50, MI and stroke did not differ appreciably across quintiles of BMI-21. A sensitivity analysis performed by analysing the first 15 years of follow-up after BRHS baseline yield similar results (data not presented). Moreover, associations were not materially altered by additional adjustment for social class (data not presented).

\section{DISCUSSION}

\section{Main findings}

Adiposity in middle age is a well-known risk factor for cardiovascular disease and type 2 diabetes. $^{2}$ However,

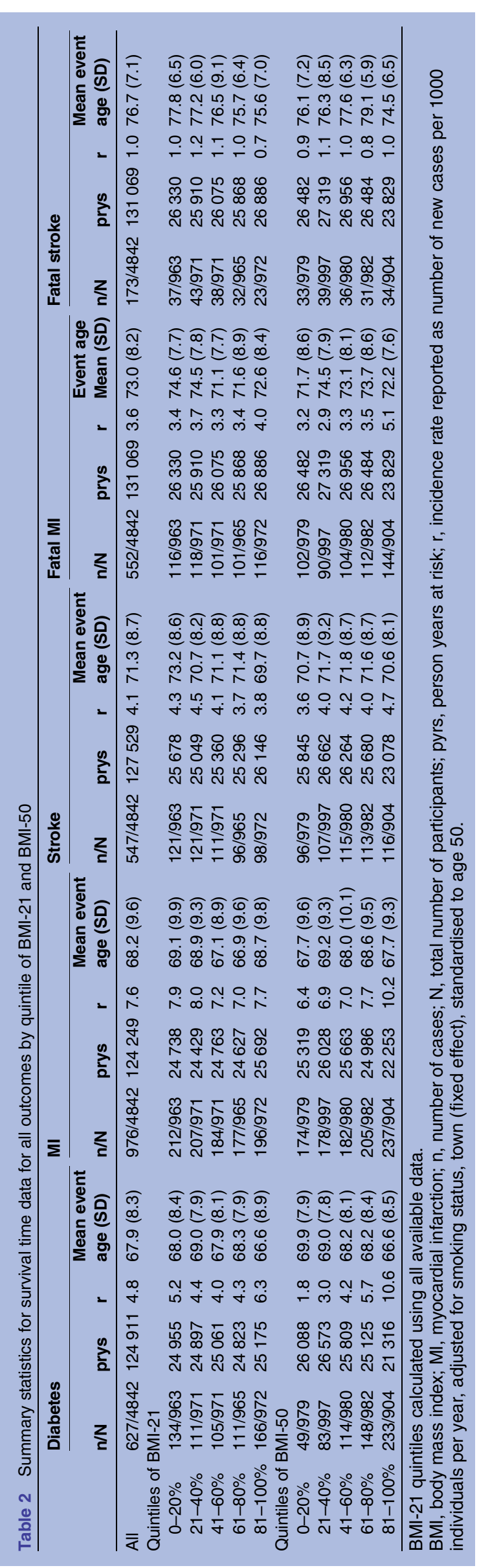


Table 3 HRs for all outcomes per $1 \mathrm{~kg} / \mathrm{m}^{2}$ higher BMl at mean ages 21 and 50 years

\begin{tabular}{|c|c|c|c|c|c|c|}
\hline \multirow[b]{2}{*}{ Outcome } & \multicolumn{3}{|c|}{ BMI-21 } & \multicolumn{3}{|c|}{ BMI-50 } \\
\hline & $\overline{\mathbf{N}}$ & HR $(95 \% \mathrm{Cl})$ & p Value & $\mathbf{N}$ & HR $(95 \% \mathrm{Cl})$ & p Value \\
\hline Diabetes & 4842 & 1.06 (1.04 to 1.09$)$ & $<0.001$ & 4842 & 1.21 (1.18 to 1.24$)$ & $<0.001$ \\
\hline MI & 4842 & 0.99 (0.97 to 1.02$)$ & 0.63 & 4842 & 1.06 (1.04 to 1.08$)$ & $<0.001$ \\
\hline Stroke & 4842 & 0.99 (0.96 to 1.02$)$ & 0.48 & 4842 & 1.04 (1.01 to 1.07$)$ & 0.010 \\
\hline Fatal MI & 4842 & 1.01 (0.98 to 1.04$)$ & 0.35 & 4842 & 1.07 (1.04 to 1.10$)$ & $<0.001$ \\
\hline Fatal stroke & 4842 & $0.97(0.92$ to 1.03$)$ & 0.29 & 4842 & 1.02 (0.97 to 1.07$)$ & 0.45 \\
\hline
\end{tabular}

HR for the effect of a $1 \mathrm{~kg} / \mathrm{m}^{2}$ increase in BMI, adjusted for age, smoking at 50 years of age and town (fixed effect).

$\mathrm{BMI}$, body mass index; MI, myocardial infarction; $\mathrm{N}$, total number of participants.

less is known about the impact of high BMI from early adult life on these outcomes, as long-term cohort studies (particularly from birth) rarely have follow-up to an age when cardiometabolic outcomes readily occur. This study provides important insight into the role of BMI, as a measure of adiposity in early adult life on cardiovascular and diabetes risks from middle age. BMI in early adult life was independently associated with later diabetes risk, but not with MI and stroke risks. BMI in middle age was more strongly associated with type 2 diabetes, and was also associated with MI and stroke risks.

\section{Relation to earlier studies}

Our findings are coherent with established evidence showing that adiposity in middle age shows strong, graded associations, most strongly with type 2 diabetes but also with CHD and stroke. ${ }^{2} 511{ }^{21}$ The finding that BMI in early adult life is associated with the subsequent incidence of diabetes is consistent with recent prospective reports linking higher levels of adiposity in early adult life to diabetes risks ${ }^{22-25}$ and with recent reports suggesting that longer duration of adiposity (particularly from early adult life) is related to diabetes risk. ${ }^{26-29}$ It is also consistent with reported associations between BMI in early adult life and insulin resistance and glycaemia, both in the present study ${ }^{20}$ and in other cohorts. ${ }^{30}$ This is also compatible with a recent large study of Israeli army recruits, which showed that high BMI in adolescence was strongly related to metabolic disorders in later life. ${ }^{24}$ This study also showed that adolescents with higher BMI who become lean in adulthood, do not have an increase and may have a reduction in their risk of diabetes. ${ }^{24}$ This is consistent with our finding that men who were overweight at 21 but not at 50 had similar or possibly lower levels of diabetes than those who were not overweight at any time, and with experimental evidence showing that weight loss has a marked effect on diabetes risk. ${ }^{31}$

Earlier studies and reviews have suggested that higher levels of adiposity in adolescence and early adult life may be associated with risks of $\mathrm{CHD},{ }^{12} 3233$ at variance with our findings for MI and stroke here. However, the independence of the early BMI-CHD associations has not so far been confirmed. ${ }^{12}{ }^{32}$ Moreover, in the present study, there were few participants with high levels of body fatness in early adult life, limiting the power of the study to detect associations between early BMI and cardiovascular disease, which would be expected to be weaker than those for diabetes. While BMI has been strongly correlated with total and visceral body fat in previous studies of adults, it should be acknowledged that BMI as a measurement of adiposity in these young men may be more closely related to lean muscle mass than to fat mass. ${ }^{34}{ }^{35}$ It is also possible that selection bias may have influenced the findings, particularly the possibility that men with high BMI-21 levels developed CHD in early middle age, making their inclusion in the study less likely. However, the marginally higher BMI-50 among men excluded from analysis compared with those included (approximately $0.2 \mathrm{~kg} / \mathrm{m}^{2}$ ), and consistency of associations between early BMI and CHD risk between 15 and 30 years of follow-up makes this less likely.

\section{Strengths and limitations}

This investigation is based on a geographically and socially representative cohort study with high response rates and exceptionally high follow-up rates. Among men who took part in the baseline examination, it was possible using two new sources of information, military health records and participant recall, to obtain information on BMI at 21 years for almost two-thirds of study participants $(65 \%)$. Information from military records was documented methodically at the time of measurement and would be expected to have a high degree of validity. Among men with data from both sources, recalled data were substantially consistent with military record data, and allowed adjustment for a small bias in recalled weight. Although the analyses were based on two-thirds of the original cohort, and therefore being based on a healthy survivor group, baseline BMI and cardiovascular risk factor profiles in men who were or were not included in the present analyses did not differ markedly, suggesting that selection bias is unlikely to have led to underestimation of potential associations between BMI in early adult life and later risks of diabetes and cardiovascular disease. This is consistent with other evidence suggesting that selection bias is unlikely to have a marked influence on exposure-outcome associations. ${ }^{36}$ However, the limited number of study participants with 
Table 4 HRs for all outcomes by patterns of high BMl at mean ages 21 and 50 years

\begin{tabular}{|c|c|c|c|c|c|c|c|c|}
\hline $\begin{array}{l}\text { BMI } \\
\text { trajectory }\end{array}$ & $\mathbf{N}$ & $\begin{array}{l}\text { BMI-21 mean } \\
\text { (SD) }\end{array}$ & $\begin{array}{l}\text { BMI-50 mean } \\
\text { (SD) }\end{array}$ & $\begin{array}{l}\text { Diabetes } \\
\text { HR }(95 \% \mathrm{Cl})\end{array}$ & $\begin{array}{l}\text { MI } \\
\text { HR }(95 \% \mathrm{Cl})\end{array}$ & $\begin{array}{l}\text { Stroke } \\
\text { HR (95\% Cl) }\end{array}$ & $\begin{array}{l}\text { Fatal MI } \\
\text { HR (95\% CI) }\end{array}$ & $\begin{array}{l}\text { Fatal } \\
\text { HR }(95 \% \mathrm{CI})\end{array}$ \\
\hline $0-0$ & 3055 & $20.6(1.7)$ & $23.9(2.1)$ & 1 & 1 & 1 & 1 & 1 \\
\hline $1-0$ & 637 & $24.9(1.7)$ & $25.2(1.6)$ & $0.81(0.60$ to 1.08$)$ & $0.95(0.78$ to 1.17$)$ & 0.81 (0.62 to 1.08$)$ & 1.05 (0.81 to 1.38$)$ & 0.65 (0.38 to 1.12$)$ \\
\hline $0-1$ & 574 & $21.2(1.9)$ & $29.3(2.0)$ & $3.02(2.45 \text { to } 3.73)^{a}$ & $1.63(1.37 \text { to } 1.95)^{a}$ & $1.25(0.98$ to 1.60$)$ & $1.80(1.44 \text { to } 2.26)^{a}$ & $1.12(0.72$ to 1.74$)$ \\
\hline $1-1$ & 576 & $26.2(2.9)$ & $29.9(2.2)$ & $2.84(2.32 \text { to } 3.48)^{a}$ & $1.28(1.06 \text { to } 1.56)^{b}$ & $1.01(0.77$ to 1.32$)$ & $1.51(1.17 \text { to } 1.94)^{b}$ & $0.92(0.56$ to 1.53$)$ \\
\hline
\end{tabular}

Table 5 HRs for the associations between BMI at mean age 50 years and all outcomes, stratified by BMI at mean age 21 years

\begin{tabular}{|c|c|c|c|c|c|c|c|c|c|c|}
\hline & \multicolumn{2}{|c|}{ Diabetes } & \multicolumn{2}{|l|}{ MI } & \multicolumn{2}{|c|}{ Stroke } & \multicolumn{2}{|c|}{ Fatal MI } & \multicolumn{2}{|c|}{ Fatal stroke } \\
\hline & $\mathbf{N}$ & $\begin{array}{l}\text { HR } \\
(95 \% \mathrm{Cl})\end{array}$ & $\mathbf{N}$ & HR (95\% Cl) & $\mathbf{N}$ & HR (95\% Cl) & $\mathbf{N}$ & HR (95\% Cl) & $\mathbf{N}$ & HR (95\% Cl) \\
\hline & $\begin{array}{l}4842 \\
s\end{array}$ & $1.21(1.18 \text { to } 1.24)^{\mathrm{a}}$ & 4842 & $1.06(1.04 \text { to } 1.08)^{\mathrm{a}}$ & 4842 & $1.04(1.01 \text { to } 1.07)^{\mathrm{b}}$ & 4842 & $1.07(1.04 \text { to } 1.10)^{\mathrm{a}}$ & 4842 & $1.02(0.97$ to 1.07$)$ \\
\hline $0-20 \%$ & 963 & $1.17(1.11 \text { to } 1.23)^{\mathrm{a}}$ & \multicolumn{7}{|c|}{ BMI-21 quintiles } & $1.07(0.95$ to 1.21$)$ \\
\hline $21-40 \%$ & 971 & $1.30(1.20 \text { to } 1.40)^{\mathrm{a}}$ & 971 & $1.08(1.02 \text { to } 1.14)^{\mathrm{b}}$ & 971 & $1.03(0.96$ to 1.11$)$ & 971 & $1.07(0.99$ to 1.15$)$ & 971 & 0.93 (0.82 to 1.06$)$ \\
\hline $41-60 \%$ & 971 & $1.24(1.16 \text { to } 1.32)^{\mathrm{a}}$ & 971 & $1.10(1.04 \text { to } 1.16)^{\mathrm{a}}$ & 971 & $1.09(1.02 \text { to } 1.17)^{b}$ & 971 & $1.12(1.05 \text { to } 1.21)^{\mathrm{b}}$ & 971 & 1.04 (0.91 to 1.18$)$ \\
\hline $61-80 \%$ & 965 & $1.29(1.21 \text { to } 1.38)^{\mathrm{a}}$ & 965 & $1.11(1.05 \text { to } 1.17)^{\mathrm{a}}$ & 965 & $1.05(0.97$ to 1.14$)$ & 965 & 1.07 (0.99 to 1.15$)$ & 965 & 1.07 (0.93 to 1.23$)$ \\
\hline $81-100 \%$ & 972 & $1.27(1.21 \text { to } 1.34)^{a}$ & 972 & $1.06(1.01 \text { to } 1.11)^{b}$ & 972 & $1.06(0.998$ to 1.14$)$ & 972 & $1.09(1.03 \text { to } 1.16)^{b}$ & 972 & 1.09 (0.97 to 1.23$)$ \\
\hline rend & & 0.19 & & 0.82 & & & & 0.63 & & 0.47 \\
\hline
\end{tabular}

$\mathrm{p}$ trend

0.82

0.62

0.47

HR for the effect of a $1 \mathrm{~kg} / \mathrm{m}^{2}$ increase in BMI in middle adulthood, adjusted for age, smoking status in middle life and town (fixed effect).

${ }^{a} \mathrm{p}<0.001,{ }^{b} \mathrm{p}<0.05$.

BMI, body mass index; MI, myocardial infarction; N, number of participants; $p$ trend, $p$ value for trend across groups regarding the effect of BMI-50 (obtained from metaregression). 
high levels of BMI in early life will have limited the power of the study for detection of the effects of BMI in early adult life on risks of MI and stroke, though they were detectable for diabetes. A further limitation of the study is the absence of information on weight between age 21 years and study entry (between 40 and 59 years) making accurate determination of duration of adiposity between early adult life and middle age infeasible.

The analytic approaches taken in this report correspond with those in other recent studies ${ }^{37-40}$ in avoiding adjustment for adiposity levels at different ages; results based on mutual adjustment for adiposity measures at different stages of the life course (which are highly intercorrelated) are likely to be misleading. ${ }^{32} 4142$ The approach taken has therefore focused on the comparative strength and consistency of independent associations between BMI at each age time point (in early and middle age) and cardiometabolic outcomes in later life. Moreover, we have assessed how different patterns and potentially cumulative/combined effects of high BMI in early and middle age impact on cardiometabolic outcomes. Our earlier work has demonstrated the potential for confusion when reparameterising statistical models examining the effect of life course BMI on disease outcomes. $^{20}$

While findings from this study are likely to be generalisable to middle-aged and older white men, relevance to women or a similar age (who show different patterns and trends in body composition, eg, greater losses in muscle mass with age), and other ethnic groups remains to be established. BMI is only a proxy measure of adiposity, and high levels of BMI may not fully capture those that are overweight or obese, especially in historic cohorts. Moreover, the degree to which BMI captures true adiposity differs with age, as ageing is associated with significant changes in body composition. ${ }^{43}$

\section{CONCLUSION}

This study provides novel and potentially important information on the role of BMI in early adult life on long-term cardiovascular and diabetes risk, based on the linkage of military service records from early adult life to an established cohort recruited in middle age. The results suggest that BMI in early adult life may have an independent influence on later type 2 diabetes risk rather than on cardiovascular disease. However, the results of the life course analyses presented here suggest that the increase in diabetes risk associated with high early adult BMI may be particularly important among men who have an elevated BMI in middle age; the absence of an increase in diabetes risk among men who had a high early BMI but a normal BMI in middle age suggests that the effects of high early BMI on diabetes may be reversible at least in part.

Contributors All Authors read and agree with the manuscript's results and conclusions. CGO, ARR, DGC, SGW and PHW designed the study and raised funding. CGO, DGC, AKW and LL collected data and enrolled participants. VVK and AKW undertook data management. VVK and OP analysed the data.
CGO wrote the first draft of the report/abstract, to which all authors contributed. CGO is responsible for data integrity.

Funding This work was supported by a project grant from the British Heart Foundation (PG/10/030/28330). The British Regional Heart Study is supported by a British Heart Foundation Programme Grant (RG/08/013/25942).

Competing interests None declared.

Ethics approval Ethical approval for the main cohort study was obtained from the relevant local research ethics committees and subsequently from the London Multicentre Research Ethics Committee and its successor, the Research Ethics Committee for London-Central (approval reference MREC/ 02/02/91). Ethical approval for the retrospective study of military records was obtained from the London Multicentre Research Ethics Committee as a Substantial Amendment to the original protocol.

Provenance and peer review Not commissioned; externally peer reviewed.

Data sharing statement No additional data are available.

Open Access This is an Open Access article distributed in accordance with the terms of the Creative Commons Attribution (CC BY 4.0) license, which permits others to distribute, remix, adapt and build upon this work, for commercial use, provided the original work is properly cited. See: http:// creativecommons.org/licenses/by/4.0/

\section{REFERENCES}

1. Wormser D, Kaptoge S, Di AE, et al. Separate and combined associations of body-mass index and abdominal adiposity with cardiovascular disease: collaborative analysis of 58 prospective studies. Lancet 2011;377:1085-95.

2. Whitlock G, Lewington S, Sherliker P, et al. Body-mass index and cause-specific mortality in 900000 adults: collaborative analyses of 57 prospective studies. Lancet 2009;373:1083-96.

3. Shaper AG, Wannamethee SG, Walker M. Body weight: implications for the prevention of coronary heart disease, stroke, and diabetes mellitus in a cohort study of middle aged men. BMJ 1997;314:1311-17.

4. Wang Y, Rimm EB, Stampfer MJ, et al. Comparison of abdominal adiposity and overall obesity in predicting risk of type 2 diabetes among men. Am J Clin Nutr 2005;81:555-63.

5. Shai I, Jiang R, Manson JE, et al. Ethnicity, obesity, and risk of type 2 diabetes in women: a 20-year follow-up study. Diabetes Care 2006;29:1585-90.

6. Ogden CL, Carroll MD, Curtin LR, et al. Prevalence of overweight and obesity in the United States, 1999-2004. JAMA 2006;295:1549-55.

7. James WP. The epidemiology of obesity: the size of the problem. $J$ Intern Med 2008;263:336-52.

8. Finucane MM, Stevens GA, Cowan MJ, et al. National, regional, and global trends in body-mass index since 1980: systematic analysis of health examination surveys and epidemiological studies with 960 country-years and 9.1 million participants. Lancet 2011;377:557-67.

9. Herman KM, Craig CL, Gauvin L, et al. Tracking of obesity and physical activity from childhood to adulthood: the Physical Activity Longitudinal Study. Int J Pediatr Obes 2009;4:281-8.

10. Yang $X$, Telama R, Leskinen $\mathrm{E}$, et al. Testing a model of physical activity and obesity tracking from youth to adulthood: the cardiovascular risk in young Finns study. Int J Obes (Lond) 2007;31:521-7.

11. Kopelman P. Health risks associated with overweight and obesity. Obes Rev 2007;8(Suppl 1):13-17.

12. Owen $C G$, Whincup $P H$, Orfei $L$, et al. Is body mass index before middle age related to coronary heart disease risk in later life? Evidence from observational studies. Int J Obes (Lond) 2009;33:866-77.

13. Kuh D, Ben-Shlomo Y. A life course approach to chronic disease epidemiology. 2nd edn. Oxford, UK: Oxford University Press, 2004

14. Bynner JM. 1970 British Cohort Study: twenty six-year follow-up, 1996 [computer file]. Colchester, Essex: UK Data Archive [distributor] 2003;SN 3833.

15. Power C, Elliott J. Cohort profile: 1958 British birth cohort (National Child Development Study). Int J Epidemiol 2006;35:34-41.

16. Wadsworth M, Kuh D, Richards M, et al. Cohort profile: the 1946 National Birth Cohort (MRC National Survey of Health and Development). Int J Epidemiol 2006;35:49-54.

17. Walker M, Whincup PH, Shaper AG. The British Regional Heart Study 1975-2004. Int J Epidemiol 2004;33:1185-92. 
18. Rose GA, Blackburn H, Gillum RF, et al. Cardiovascular survey methods. 2nd edn. Geneva, Switzerland: World Health Organization, 1982.

19. Fletcher RT. PULHEEMS, a new system of medical classification. BMJ 1949;1:83-8.

20. Kapetanakis VV, Rudnicka AR, Wathern AK, et al. Adiposity in early, middle and later adult life and cardiometabolic risk markers in later life; findings from the British regional heart study. PLOS ONE 2014;9: e114289.

21. Wannamethee SG, Shaper AG, Walker M. Overweight and obesity and weight change in middle aged men: impact on cardiovascular disease and diabetes. J Epidemiol Community Health 2005;59:134-9.

22. Hypponen E, Power C, Smith GD. Prenatal growth, BMI, and risk of type 2 diabetes by early midlife. Diabetes Care 2003;26:2512-17.

23. Schmidt M, Johannesdottir SA, Lemeshow S, et al. Obesity in young men, and individual and combined risks of type 2 diabetes, cardiovascular morbidity and death before 55years of age: a Danish 33-year follow-up study. BMJ Open 2013;3:pii: e002698.

24. Tirosh A, Shai I, Afek A, et al. Adolescent BMI trajectory and risk of diabetes versus coronary disease. N Engl J Med 2011;364:1315-25.

25. The NS, Richardson AS, Gordon-Larsen P. Timing and duration of obesity in relation to diabetes: findings from an ethnically diverse, nationally representative sample. Diabetes Care 2013;36:865-72.

26. Wannamethee SG, Shaper AG. Weight change and duration of overweight and obesity in the incidence of type 2 diabetes. Diabetes Care 1999;22:1266-72.

27. Bouchard DR, Porneala B, Janssen I, et al. Risk of type 2 diabetes and cumulative excess weight exposure in the Framingham Offspring Study. J Diabetes Complications 2013;27:214-18.

28. Abdullah A, Stoelwinder J, Shortreed S, et al. The duration of obesity and the risk of type 2 diabetes. Public Health Nutr 2011;14:119-26.

29. Lee JM, Gebremariam A, Vijan S, et al. Excess body mass index-years, a measure of degree and duration of excess weight, and risk for incident diabetes. Arch Pediatr Adolesc Med 2012;166:42-8.

30. Power $\mathrm{C}$, Thomas $\mathrm{C}$. Changes in $\mathrm{BMI}$, duration of overweight and obesity, and glucose metabolism: 45years of follow-up of a birth cohort. Diabetes Care 2011;34:1986-91.

31. Hamman RF, Wing RR, Edelstein SL, et al. Effect of weight loss with lifestyle intervention on risk of diabetes. Diabetes Care 2006;29:2102-7.
32. Lloyd LJ, Langley-Evans SC, McMullen S. Childhood obesity and adult cardiovascular disease risk: a systematic review. Int J Obes (Lond) 2010;34:18-28.

33. Park $\mathrm{MH}$, Sovio $\mathrm{U}$, Viner RM, et al. Overweight in childhood, adolescence and adulthood and cardiovascular risk in later life: pooled analysis of three British birth cohorts. PLOS ONE 2013;8:e70684

34. Krachler B, Volgyi E, Savonen K, et al. BMI and an anthropometry-based estimate of fat mass percentage are both valid discriminators of cardiometabolic risk: a comparison with DXA and bioimpedance. J Obes 2013;2013:862514.

35. Phan TL, Maresca MM, Hossain J, et al. Does body mass index accurately reflect body fat? A comparison of anthropometric measures in the longitudinal assessment of fat mass. Clin Pediatr (Phila) 2012;51:671-7.

36. Pizzi $\mathrm{C}$, De SB, Merletti F, et al. Sample selection and validity of exposure-disease association estimates in cohort studies. J Epidemiol Community Health 2011;65:407-11.

37. Li L, Law C, Power C. Body mass index throughout the life-course and blood pressure in mid-adult life: a birth cohort study. $J$ Hypertens 2007;25:1215-23.

38. Sun Q, Townsend MK, Okereke OI, et al. Adiposity and weight change in mid-life in relation to healthy survival after age 70 in women: prospective cohort study. BMJ 2009;339:b3796.

39. Houston DK, Ding J, Nicklas BJ, et al. Overweight and obesity over the adult life course and incident mobility limitation in older adults: the health, aging and body composition study. Am J Epidemiol 2009;169:927-36

40. Sabia S, Kivimaki M, Shipley MJ, et al. Body mass index over the adult life course and cognition in late midlife: the Whitehall II Cohort Study. Am J Clin Nutr 2009;89:601-7.

41. Tu YK, West R, Ellison GT, et al. Why evidence for the fetal origins of adult disease might be a statistical artifact: the "reversal paradox" for the relation between birth weight and blood pressure in later life. Am J Epidemiol 2005;161:27-32.

42. Park MH, Falconer C, Viner RM, et al. The impact of childhood obesity on morbidity and mortality in adulthood: a systematic review. Obes Rev 2012;13:985-1000.

43. Wannamethee SG, Shaper AG, Lennon L, et al. Decreased muscle mass and increased central adiposity are independently related to mortality in older men. Am J Clin Nutr 2007;86:1339-46. 